\title{
Where are they now? Tracking the Mediterranean lionfish invasion via local dive centers
}

\author{
Elizabeth W. Phillips *, Alexander Kotrschal \\ Behavioural Ecology, Wageningen University, 6708PB Wageningen, Netherlands
}

\section{A R T I C L E I N F O}

\section{Keywords:}

Lessepsian invasion

Lionfish

Pterois miles

Citizen science

Mediterranean sea

\begin{abstract}
A B S T R A C T
Invasive species are globally on the rise due to human-induced environmental change and are often a source of harm to their new ecosystems. Tracking the spread of invaders is crucial to better manage invasive species, and citizen science is often used to collect sighting data. However, this can be unreliable due to the general public's limited expertise for accurate identification and a lack of clear absence data. Here, we introduce a refined method of citizen science by tracking the spread of the invasive lionfish (Pterois miles) in the Mediterranean Sea using dive centers' expertise on local marine wildlife. We contacted 1131 dive centers on the Mediterranean coast via email and received 216 responses reporting whether or not lionfish were present in their area and, if present, the year they were first sighted. Currently, lionfish sightings are observed in the eastern half of the Mediterranean, though the front is continuing to move west with the furthest sighting as far as Corfu, Greece $\left(19.939423^{\circ} \mathrm{E}\right.$, $39.428017^{\circ} \mathrm{N}$ ). In 2020 , lionfish also expanded their invasive range north on the Turkish Aegean coast to Karaburun $\left(26.520657^{\circ} \mathrm{E}, 38.637033^{\circ} \mathrm{N}\right)$, showing that the invasion is ongoing. We found that the invasive range is now exceeding previous invasion models, highlighting the need for additional research on lionfish biology to inform management efforts. Continuous monitoring of invasive fronts based on dive center reports and a better understanding of what makes lionfish so invasive is crucial to creating effective management strategies and mitigating their negative impact on native ecosystems.
\end{abstract}

\section{Introduction}

As humans continue to shape and modify their environment, animals often find themselves in novel situations to which they must react and adapt. One of these situations is when direct human transport or manmade constructions allow animals to move from one area to the other and become invasive. Globally, invasive species have been on the rise due to human-induced environmental change, and often cause ecological damage to the areas they invade (Simberloff et al., 2013; Cassey et al., 2005). A crucial step to creating effective management strategies for invasive species is tracking their introduction and expansion into new regions. Often citizen science databases, like "Is it Alien to you? Share it!!!", Seawatchers or IUCN MedMIS, are used by researchers to gain insight into new invasive species or expansion on the front of existing invasive species (Dimitriadis et al., 2020; Katsanevakis et al., 2020). These databases offer a platform for the general public to report and collect data for professional scientists to use in a collaborative effort, often tracking species sightings across larger areas (Larson et al., 2020). Although these types of reports often allow researchers to gain larger quantities of data than what could be collected alone, citizen scientists may not have the expertise to reliably identify unfamiliar species and usually these reports only list confirmed sightings, so clear absence data is not obtainable (Larson et al., 2020; Crall et al., 2010; Sandahl and Tøttrup, 2020).

Species tracking using citizen science is a common method used to collect sighting data on invasive marine species in the Mediterranean Sea. In 1869 the Suez Canal opened up a new passageway for marine organisms to move between the Red Sea and the Mediterranean either by currents carrying pelagic larvae or by adult movement through the channel (Galil et al., 2014). Though the canal is open to movement from either direction, species mainly migrate from the Red Sea to the Mediterranean because of current direction and increased habitat flexibility and biodiversity in Red Sea-native organisms (reviewed in Mavruk and Avsar, 2008). These "Lessepsian species" totaled 63 by 2008 and have been on the rise due to the recent expansion of the Suez Canal (Galil et al., 2015; Mavruk and Avsar, 2008).

One of these species, the lionfish (Pterois miles) was rarely sighted in the Mediterranean until 2012 when sightings began to rise and their

\footnotetext{
* Corresponding author. De Elst 1, 6708WD Wageningen, Netherlands.

E-mail addresses: elizabeth.phillips@wur.nl (E.W. Phillips), alexander.kotrschal@wur.nl (A. Kotrschal).
} 
invasion commenced (Bariche et al., 2013; Jimenez et al., 2016; Golani and Sonin, 1992; Kletou et al., 2016). With their recent expansion into the Mediterranean, concern has risen about its ecological impacts based on the well-studied lionfish invasion in the Atlantic. Release of lionfish from the aquarium trade in Florida, USA has allowed them to spread throughout the Western Atlantic Ocean and Caribbean Sea with numerous detrimental effects on native communities, including decreases in biodiversity, reef deterioration, and economic loss in the fishing industry (Côté et al., 2013; Lesser and Slattery, 2011; Henderson, 2012). Their rapid expansion has been attributed to characteristics like their high fecundity, venomous spines, generalist diet, and habitat flexibility (Côté et al., 2013; Galloway and Porter, 2019; Peake et al., 2018; Rojas-Vélez et al., 2019). Studies on Mediterranean lionfish have revealed that similar to those in the Atlantic, these invasive fish are larger than their native counterparts, have high reproductive rates year-round, and prey on a large range of fish that consists of some that are economically important in the area (Savva et al., 2020). Genetic studies of lionfish from both invasive ranges suggests that only a few individuals were originally introduced and responsible for the subsequent establishment and invasion, suggesting that these fish are resilient even at low numbers (Bariche et al., 2017; Stern et al., 2019; Hamner et al., 2007). These characteristics are likely to facilitate the lionfish's invasion in the Mediterranean as well, with similar negative impacts on the Mediterranean ecosystem if allowed to spread (Kletou et al., 2016; Ulman et al., 2020; Galanidi et al., 2018). Even with these concerns, legislation is slow to take action and public awareness remains low (Kleitou et al, 2019, 2021).

Initial reports of the invasion showed lionfish spread and establishment around Cyprus and on the Levantine Coast located at the eastern border of the Mediterranean, but the most recent report documented sightings as far west as the Greek Ionian coast, Libya, as well as single sightings of lionfish in Italy and Tunisia (Azzurro et al., 2017; Dimitriadis et al., 2020). These reports come from small studies of individual countries, or use citizen science databases to track the spread throughout the entire Mediterranean Sea (Azzurro and Bariche, 2017; Özbek et al., 2017; Kletou et al., 2016; Katsanevakis et al., 2020; Dimitriadis et al., 2020). To create a more complete and reliable overview of the lionfish invasion in the Mediterranean, we need to utilize people that have enough local expertise to be able to reliably identify the invasive fish and can say with some confidence that there are no lionfish present if they do not see them. This type of local underwater expertise can be found at dive centers, and centers can be found all over the Mediterranean. Dive instructors have been found to have species knowledge equal with scientific divers and significantly higher than average for recreational divers, with particularly high scores for species recognition capabilities (Isabel et al., 2021). In this way, the use of dive centers in citizen science could create a more refined method of citizen science with a smaller chance of false identification of species. We conducted a survey of dive centers around the Mediterranean and asked them to report if they have seen lionfish in their area, and if so, when they first appeared in order to create the most up-to-date report of the lionfish invasion in this area.

\section{Methods}

\subsection{Dive center search}

Google Maps was used to locate dive centers situated along the Mediterranean Sea using the search term "dive center". The search was started at the mouth of the Suez Canal and continued westward along the coast, circling back to the start point, and included all islands located in the sea. Care was taken to ensure all costal area was searched and that all relevant dive center results would be revealed in an area. Search results would be considered dive centers and contacted for the survey if their name in Google Maps contained the phrase "dive center" or an equivalent in any language using the Latin alphabet, appeared in the first 20 results listed for a given area, offered tours or courses in diving (to ensure active divers on staff), and listed a website with contact information listing at least one email.

When a dive center was found that met our criteria, their website was searched for all available email addresses related to diving, which were then recorded along with the geographic coordinates of the dive center. If multiple email addresses were found, emails were sent to the most relevant email address for dive instructors. This yielded 1131 emails to dive centers. The distribution of the dive centers contacted is shown in Fig. 1.

\subsection{Survey distribution}

We contacted dive centers found through Google Maps via email and asked two questions: 1) Have you seen lionfish in your area? and 2) If so, when did you first see them? Email text was written in English and translated into 7 other languages (Arabic, French, Spanish, Italian, Turkish, Greek, and German) by native speakers when possible in order to make the survey more accessible to those who do not speak English fluently. If after 1 week no response was received from a dive center, a reminder email was sent in order to maximize the number of responses received.

\subsection{Data analysis}

Responses from individual dive centers and coordinates previously recorded during the search process were imported into ArcGIS Pro (version 2.5.1) to create maps illustrating lionfish sightings based on dive center coordinates (Esri, 2020). We chose to use dive center coordinates as locations of lionfish sightings since coastal dive centers typically use dive sites close to their dive center.

\section{Results}

After contacting 1131 dive centers, we received 216 responses. Of these responses, 75 reported sightings of lionfish in their local area and 141 reported that no lionfish were present (Fig. 1). We found that lionfish had been sighted at least once in Israel, Lebanon, Cyprus, Turkey, Greece, and Spain, while dive centers in Tunisia, Morocco, France, Italy, Malta, Slovenia, Croatia, Montenegro, and Albania only reported no sightings. With the exception of one dive center on the south-west coast of Cyprus, dive centers from the east side of the Mediterranean up until the Turkish Aegean coast and mainland Greece unanimously reported lionfish sightings. Overall, the most north-western sighting of lionfish was a singular report on the Costa Brava in Spain $\left(2.9030443^{\circ} \mathrm{E}\right.$, $41.7109527^{\circ} \mathrm{N}$ ). In the eastern half of the Mediterranean where all other sightings were located, lionfish sightings were reported as far north as Karaburun, Turkey $\left(26.5206573^{\circ} \mathrm{E} 38.6370333^{\circ} \mathrm{N}\right)$, and as far west as at Corfu Island, Greece $\left(19.9394234^{\circ} \mathrm{E} 39.4280170^{\circ} \mathrm{N}\right)$.

For reports of lionfish sighting, we also recorded the year that lionfish were first spotted in the area as reported by dive centers. We found that single lionfish sightings were observed in 1997 on a Greek island off the coast of Turkey $\left(27.3126756^{\circ} \mathrm{E} 36.8851393^{\circ} \mathrm{N}\right)$, near Tossa de mar, Spain in $2002\left(2.9030443^{\circ} \mathrm{E}, 41.7109527^{\circ} \mathrm{N}\right)$, Antalya, Turkey in 2005 $\left(30.7054499^{\circ} \mathrm{E} \quad 36.8767709^{\circ} \mathrm{N}\right)$, Ölüdeniz, Turkey in 2013 $\left(29.1116429^{\circ} \mathrm{E}, 36.5499014^{\circ} \mathrm{N}\right)$ and Yeni Iskele, Cyprus in 2014 $\left(33.949655^{\circ} \mathrm{E}, 35.312925^{\circ} \mathrm{N}\right)$. Establishment of lionfish occurred in Cyprus and Turkey by 2015, with the invasion front continuing to move west and north each year (Fig. 2). In 2016, lionfish were first spotted near the island of Crete $\left(24.3911364^{\circ} \mathrm{E} \quad 35.1907813^{\circ} \mathrm{N}\right.$ and $26.6803124^{\circ} \mathrm{E} 35.2259198^{\circ} \mathrm{N}$ ), and in 2018 they were seen off of mainland Greece in the Ionian Sea $\left(21.6503151^{\circ} \mathrm{E} 36.9944446^{\circ} \mathrm{N}\right)$. In the Aegean Sea and Ionian Sea, the furthest northern sightings as documented above were in the years 2020 and 2019, respectively. 


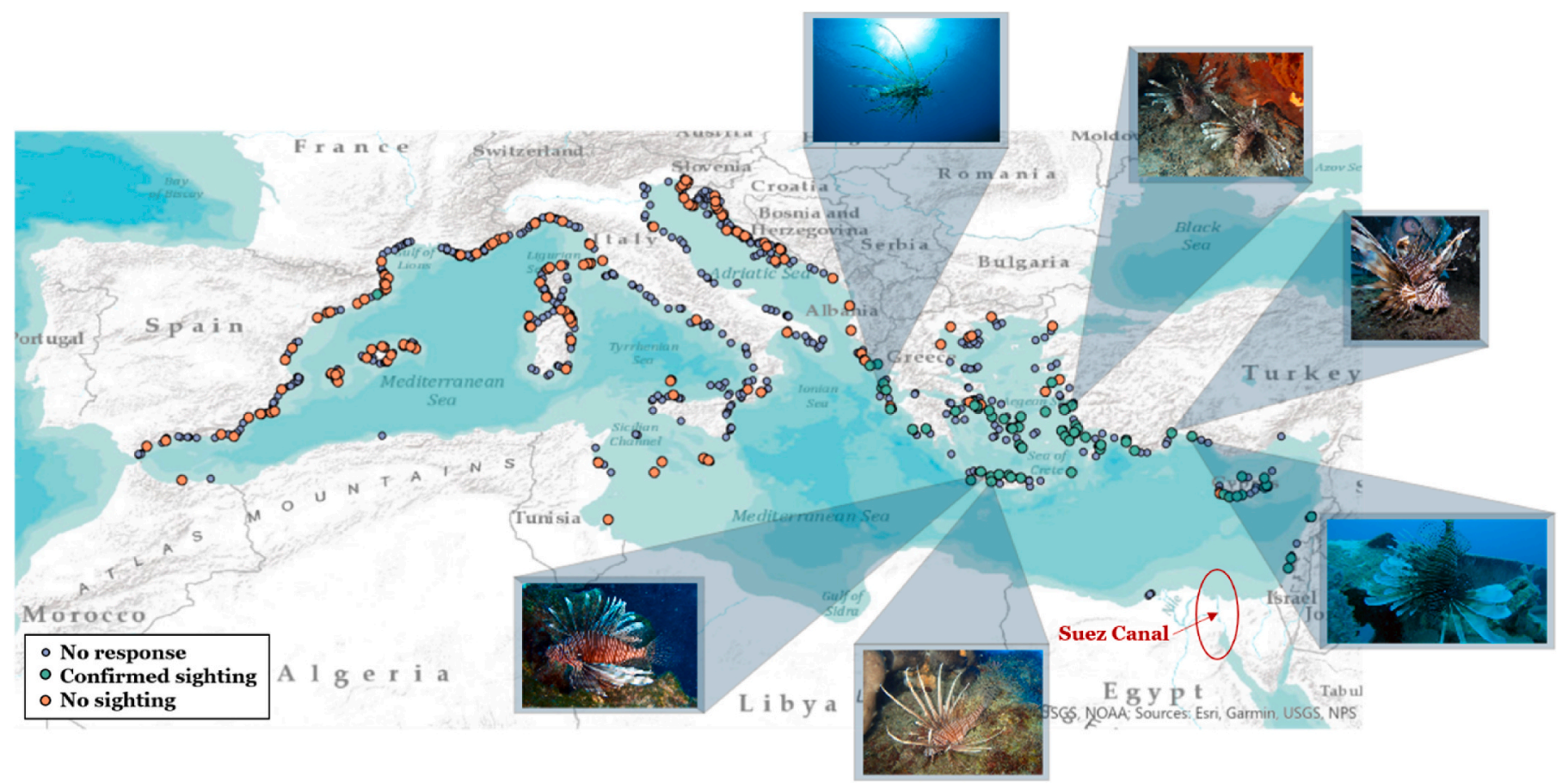

Fig. 1. Contacted dive centers and survey respondents. Each dot represents a dive center that was contacted during our survey: green dots represent survey respondents that reported sightings of lionfish, red dots are reported no-sightings, and gray dots are dive surveys that were contacted, but gave no response. Pictures of lionfish sighted in their area were provided by the following dive centers (starting at the top, moving clockwise): Fiskardo Divers (Greece), Kiwi Watersports \& Dive Center (Turkey), Pearl Diving Center (Turkey), Scuba Side Diving Center (Turkey), Kalypso Dive Center \& School (Crete), Paradise Dive Center (Crete).

\section{Discussion}

Using our novel methodology of tapping into the local expertise of 216 of professional divers, we found that lionfish were observed irregularly around Turkey from 1997 to 2014, but establishment was first seen in Cyprus and Turkey in 2015 with multiple sightings in these areas. We found a boom of sightings during the following years with a westward movement of the front along Turkey, Crete, mainland Greece, and the South Aegean Islands. Overall, this is consistent with the invasion spread reported using citizen science and local expertise at a smaller, national scale, with a few key differences (Dimitriadis et al., 2020; Azzurro et al., 2017). First, we found reports of lionfish sightings in Turkey prior to 2012 which is previously undocumented in the literature. Though lionfish have been previously reported in the Mediterranean as early as 1992, this earliest sighting is from Israel, closer to the mouth of the Suez Canal than our reported sightings in Turkey (Golani and Sonin, 1992). Second, unlike previous reports, we did not find sightings of lionfish in Italy or Tunisia, but did document the first reported sighting to our knowledge of lionfish in Spain in 2002 (Azzurro et al., 2017; Dailianis et al., 2016). All of these sightings were of single lionfish and represented rare events when compared to previous literature from citizen science reports (Dimitriadis et al., 2020). Our methodology may have missed very rare occurrences, such as in Italy and Tunisia, but did uncover an additional rare sighting previously undocumented in Spain. Due to the time and distance between the majority of sightings found in our study and that in Spain, we speculate that lionfish sighted here were mostly likely due to aquarium release without establishment prior to the ongoing current invasion via the Suez Canal. Singular, seemingly detached sightings like these are important to document, as releases from the aquarium trade in places like the Bay of Marseilles, France are predicted to result in high invasion pressure from lionfish (Johnston and Purkis, 2014). Together, the overall consistency, but small differences in findings between our methodology and traditional citizen science show that by using a combination of these two techniques as part of citizen science initiatives could increase the accuracy of invasive species detection through a refined method of citizen science.

Although we found no further establishment of lionfish west of Corfu, Greece (reported in 2019), we found an ongoing expansion north in 2020 to Karaburun, Turkey. This movement north in recent years is noteworthy, as a thermal barrier has long been considered a prominent hindrance to lionfish invasion across the entire Mediterranean Sea. In the Atlantic Ocean, lionfish only establish in locations with mean winter temperatures above $15.3^{\circ} \mathrm{C}$, though lionfish have experimentally been shown to withstand temperatures as low as $10^{\circ} \mathrm{C}$ (Whitfield et al., 2014; Kimball et al., 2004). These isotherm boundaries are currently only present north of the lionfish sightings, though just barely, so it remains to be seen in the coming years if lionfish in the Mediterranean will be able to cross the thermal barrier and establish in more northern regions, or if they will be limited in their spread (Fig. 3; Dimitriadis et al., 2020; Johnston and Purkis, 2014). In the Atlantic, lionfish are only seen north of this barrier during summer's high temperatures, but none have been able to establish year-round. In the next decades, climate change is also predicted to push the isotherms further north, likely allowing lionfish to invade the entire Mediterranean by 2100 (Turan, 2020; Dimitriadis et al., 2020). Importantly, several models based on other biogeographic barriers such as currents predict limited spread of lionfish in the Mediterranean past their present established territories (Poursanidis, 2015; Johnston and Purkis, 2014; Poursanidis et al., 2020). Current patterns in the Mediterranean Sea are thought to cause low connectivity between suitable habitats for lionfish, limiting potential larvae spread to the west (Johnston and Purkis, 2014). However, our data shows that lionfish have spread past these assumed invasion boundaries. What other factors facilitate this spread beyond previously suggested boundaries remains unknown. Here, we offer several non-mutually exclusive explanations.

Behavioral flexibility and/or better cognitive abilities may be key to lionfish invasive success. Behavioral adaptations have been shown to increase success of invasive species across a variety of taxa (Weis and Sol, 2016). For instance, in round gobies (Neogobius melanostomus), higher dispersal potential and bolder personalities are shown in 


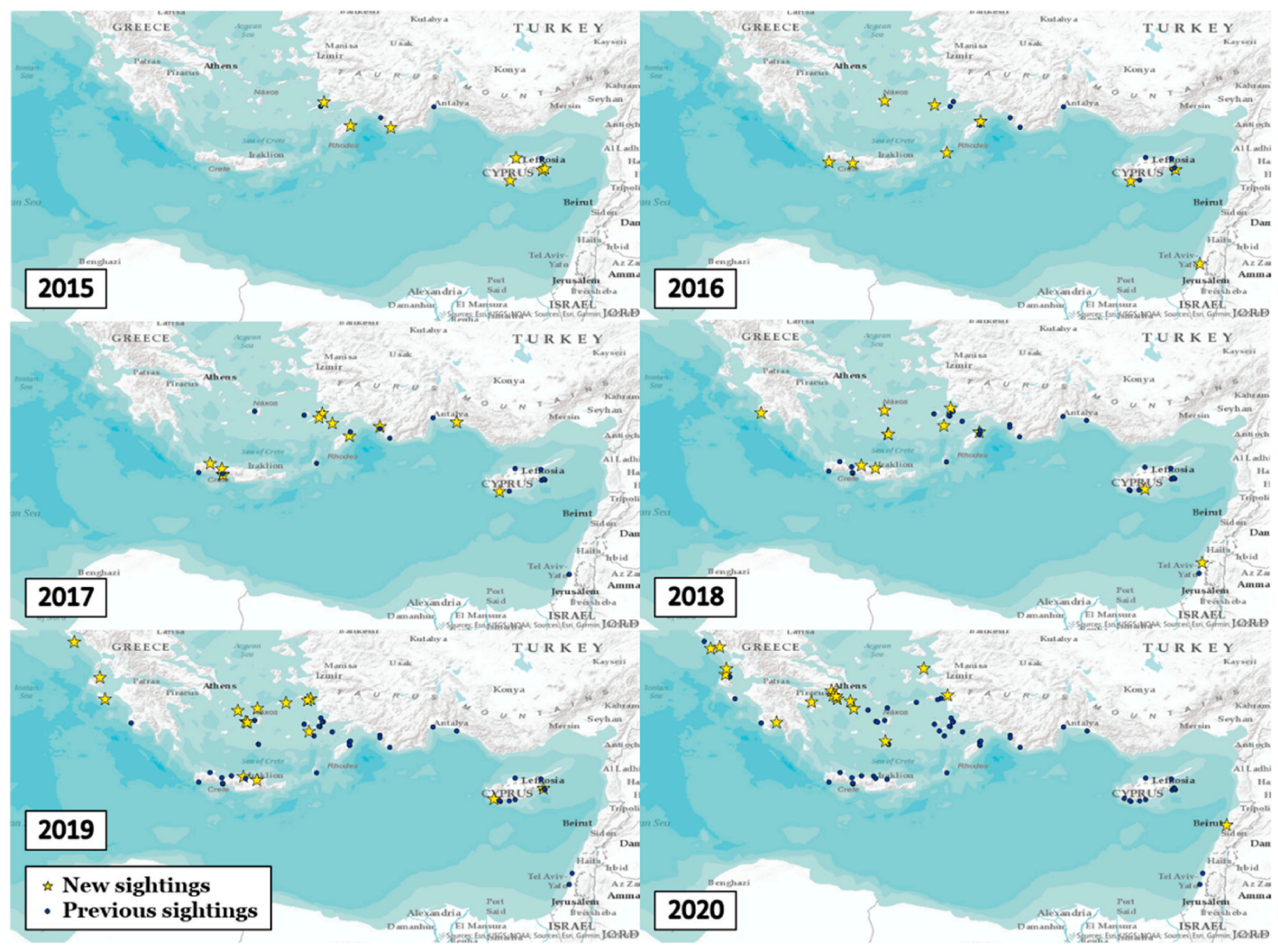

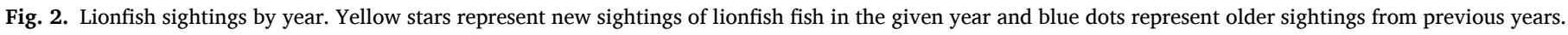

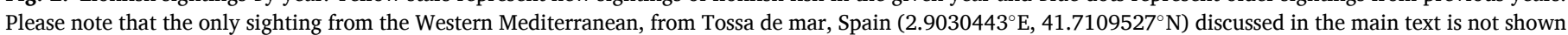
in this figure, but is important to note as a pre-2015 sighting.

individuals on the invasive front, while in the common myna (Acridotheres tristis) invasive populations have increased innovation and decreased neophobia compared to native populations (Myles-Gonzalez et al., 2015; Magory et al., 2020). We predict that lionfish in invasive territories may similarly possess different behavioral and/or cognitive traits that are more advantageous to invasive ability compared to their native counterparts. For example, post-settlement invasive lionfish may find themselves in novel environments, so better operant learning or innovative ability might help these individuals adapt, survive, and establish in new areas (Weis and Sol, 2016). In this way, habitats or environments previously thought unsuitable for lionfish might become inhabited by invasive lionfish in the upcoming years. How invasive populations in the Atlantic and the Mediterranean differ in their behavior and cognition also has yet to be investigated, as this could cause differential expansion rate and invasive ability between the two populations.

Differences in predation level by filter feeders could also impact the precision of models in predicting invasive ability. The Enemy Release Hypothesis predicts that invaders escape population controls (predators, competitors, parasites, pathogens, etc.) present in their native range, causing them to thrive in novel invasive ecosystems (Torchin and Mitchell, 2004; Mack et al., 2000). There is conflicting evidence on the presence of natural predators to adult and juvenile lionfish in both their native and invasive ranges, as a few reports have been made of grouper and moray eel predation events, but there is no clear trend of population control due to predation (Maljković et al., 2008; Bernadsky and Goulet, 1991; Mumby et al., 2011; Bos et al., 2017; Hackerott et al., 2013; Smith and Isabelle, 2021; Côté et al., 2013). In contrast, larvae predation during the pelagic phase by filter feeders has yet to be explored. Filter feeders in the native range may have evolved with lionfish to be able to feed on them as larvae, but those in invasive ranges have not, causing the higher population density of invasive lionfish compared to native populations, and further range expansion of these species then previously predicted (Darling et al., 2011). For example, a prevalent filter feeder in the Indo-Pacific, the Ascidian Herdmania momus, is also invasive in the Mediterranean via introduction through the Suez Canal (Rius and Shenkar, 2012). H. momus's invasive range does not expand as far north or west as the lionfish's however, suggesting that lionfish may have been able to spread far enough in the Mediterranean to escape the predation pressure of native filter feeders, allowing further expansion than predicted models (Çinar et al., 2006; Gewing et al., 2019). The absence of coral reefs in the Mediterranean Sea may also impact the predation pressure on lionfish larvae, as coral reef sponges are also known to decrease the abundance of pelagic larvae through filtration (Riisgård and Larsen, 2010). Finally, reduced parasite load may contribute to the rapid spread. Few studies have investigated the effect of parasite load between invasive and native lionfish, although one study has found that variation in parasite load in lionfish across the 


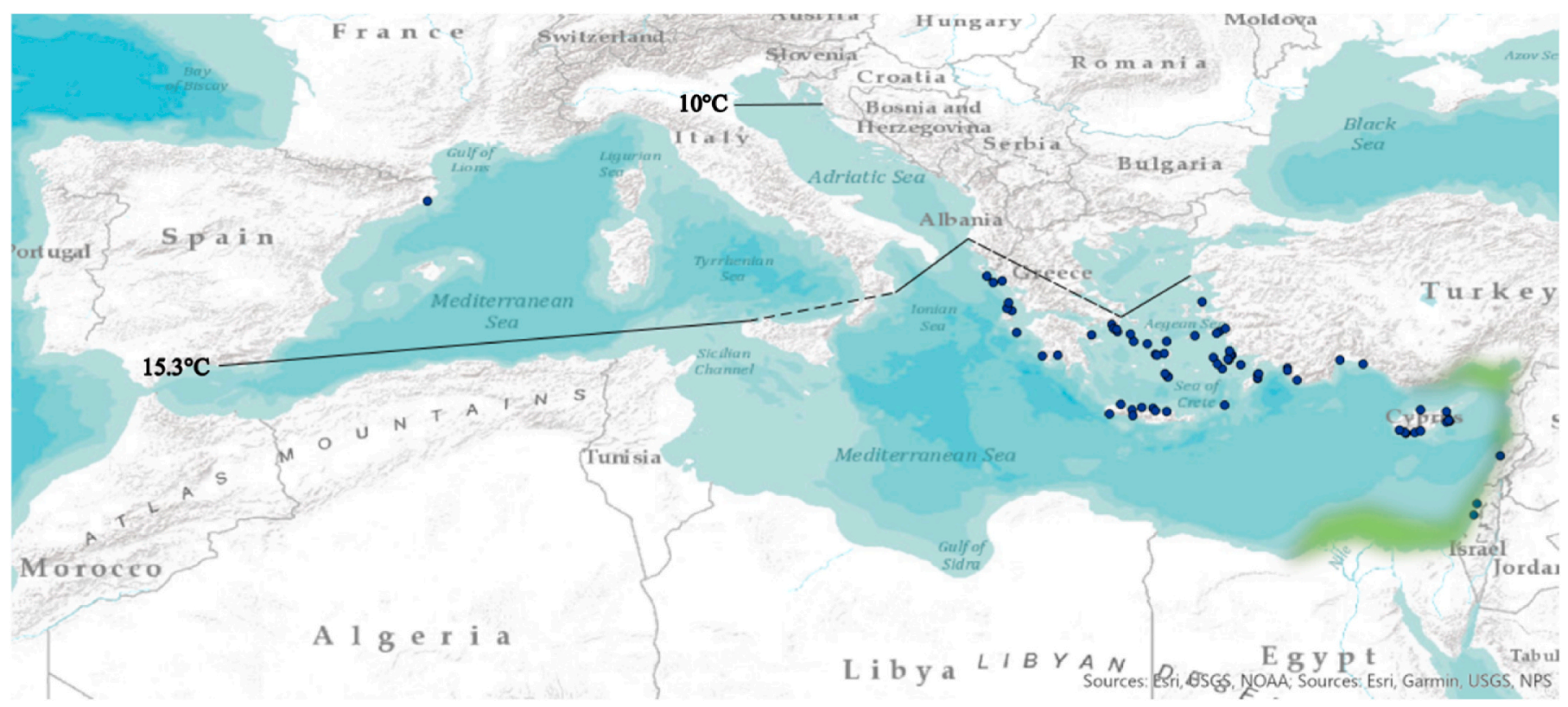

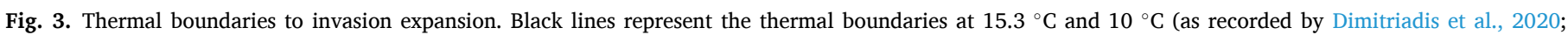

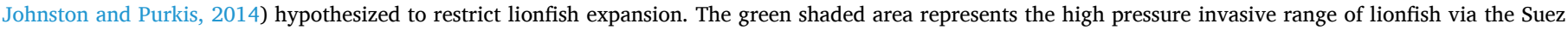
Canal as predicted by Johnston and Purkis (2014). Blue dots represent the lionfish sightings reported in our survey.

Caribbean has little effect on the health and fitness of the fish (Ramos-Ascherls et al., 2015; Sellers et al., 2015).

Another question that remains is why the Mediterranean invasion is starting now, rather than at the opening of the Suez Canal in 1869. One reason may be that the Suez Canal was recently expanded in 2015, allowing more opportunity for passage from native habitats in the Red Sea to the Mediterranean, but this may not be the only reason. For example, global warming in previous years may have led to an increased opportunity for lionfish to establish and thrive in the Mediterranean (Hoegh-Guldberg and Bruno, 2010; Gattuso et al., 2015). Lionfish may have also developed mutations causing better physiological cold resistance in invasive populations and the ability to reside closer to the temperature barrier. Additionally, adaptations that effect behavior could have made lionfish more able to adapt to Mediterranean conditions, similar to the blue tit innovation in the United Kingdom after urbanization in the 1940s. These birds learned to pierce the foil on the top of milk bottles as a novel way to obtain food in an increasingly urbanizing environment (Aplin et al., 2013). Similarly, lionfish may have learned and developed behavioral adaptations that have made them more likely to fit into an unoccupied ecological niche present in the Mediterranean, allowing them to thrive in the new niche (Poursanidis et al., 2020). These types of adaptations in invasive populations should be tested to better understand the invasive ability of various species.

\section{Conclusions}

Based on local dive center expertise, we found that lionfish established in the eastern part of the Mediterranean by 2015 and now have spread as far as the Greek Ionian coast, with clear evidence of ongoing expansion given by new sightings as recent as October 2020 $\left(23.1537875^{\circ} \mathrm{E}, 37.6378821^{\circ} \mathrm{N}\right)$. This expansion into new invasive territory demonstrates the need for continuous monitoring of this species using local expertise and development of management methods to protect native biodiversity (Galil et al., 2017). For instance, careful documentation of lionfish distribution in the Caribbean has allowed for evaluation and implementation of management strategies to reduce the lionfish population in invasive areas (de León et al., 2013). Documentation of the invasive lionfish in Bonaire and Curaçao has revealed that the promotion of volunteer lionfish hunting programs has resulted in up to 4.14-fold reduction in lionfish in fished versus unfished areas. Similar efforts are being conducted in the Mediterranean with programs such as RELIONMED-LIFE; continuous monitoring of lionfish populations and expansion will be crucial to understanding the efforts of these efforts in the Mediterranean. We also argue that reliance on citizen may not tell the whole story, as it requires the general public to reliably identify invasive species, and for citizen science campaigns for certain species to be widely advertised in the area. For example, the sighting we found in Spain might have been unreported until this point because attention is not drawn to identifying and tracking lionfish there. Local experts, like those found at dive centers, are able to notice new species due to their familiarity with the area, though they are in low numbers compared to the general public and not as abundant in non-tourist destinations, such as the southern coast of the Mediterranean Sea (Fig. 1). Ideally, these strategies should complement one another, combining the advantages of large data sets from general public citizen science, and increased accuracy in sightings from dive center reports. Finally, to create effective management strategies for lionfish populations in the Mediterranean, we need to intensify our research effort to know more about why this species is able to expand its territory so quickly, even under unfavorable conditions. Understanding the invasive potential of lionfish and other species will allow us to create more accurate invasive models and be more proactive in management strategies.

\section{Funding}

This research did not receive any specific grant from funding agencies in the public, commercial, or not-for-profit sectors.

\section{Credit author statement}

Elizabeth W Phillips: Conceptualization, Methodology, Investigation, Writing - Original Draft, Visualization; Alexander Kotrschal: Conceptualization, Methodology, Writing - Review \& Editing, Supervision.

\section{Declaration of competing interest}

The authors declare that they have no known competing financial 
interests or personal relationships that could have appeared to influence the work reported in this paper.

\section{References}

Aplin, Lucy M., Sheldon, Ben C., Morand-Ferron, Julie, 2013. Milk bottles revisited: social learning and individual variation in the blue tit, cyanistes caeruleus. Anim. Behav. 85 (6), 1225-1232. https://doi.org/10.1016/j.anbehav.2013.03.009.

Azzurro, E., Bariche, M., 2017. Local knowledge and awareness on the incipient lionfish invasion in the eastern Mediterranean Sea. Mar. Freshw. Res. 68 (10), 1950-1954. https://doi.org/10.1071/MF16358.

Azzurro, Ernesto, Stancanelli, Bessi, Di Martino, Vincenzo, Bariche, Michel, 2017. Range expansion of the common lionfish Pterois miles (bennett, 1828) in the Mediterranean Sea: an unwanted new guest for Italian waters. BioInvasions Records 6 (2), 95-98. https://doi.org/10.3391/bir.2017.6.2.01.

Bariche, M., Torres, M., Azzurro, E., 2013. The presence of the invasive lionfish Pterois miles in the Mediterranean Sea. Mediterr. Mar. Sci. 292-294.

Bariche, Michel, Kleitou, Periklis, Kalogirou, Stefanos, Bernardi, Giacomo, 2017. Genetics reveal the identity and origin of the lionfish invasion in the Mediterranean Sea. Sci. Rep. 7 (1), 1-6. https://doi.org/10.1038/s41598-017-07326-1.

Bernadsky, Gilad, Goulet, Denis, 1991. A natural predator of the lionfish, Pterois miles. American Society of Ichthyologists and Herpetologists (1), 230-231.

Bos, Arthur R., Sanad, Ashraf M., Elsayed, Khamis, 2017. Gymnothorax spp. (muraenidae) as natural predators of the lionfish Pterois miles in its native biogeographical range. Environ. Biol. Fish. 100 (6), 745-748. https://doi.org/ 10.1007/s10641-017-0600-7.

Cassey, Phillip, Blackburn, Tim M., Duncan, Richard P., Chown, Steven L., 2005. Concerning invasive species: reply to Brown and sax. Austral Ecol. 30 (4), 475-480. https://doi.org/10.1111/j.1442-9993.2005.01505.x.

Çinar, Ertan, Melih, Bilecenoglu, Murat, Öztürk, Bilal, Alp, Can, 2006. New records of alien species on the levantine coast of Turkey. Aquat. Invasions 1 (2), 84-90.

Côté, Isabelle M., Green, Stephanie J., Hixon, Mark A., 2013. Predatory fish invaders: insights from indo-pacific lionfish in the western atlantic and caribbean. Biol. Conserv. 164, 50-61. https://doi.org/10.1016/j.biocon.2013.04.014.

Crall, Alycia W., Newman, Gregory J., Catherine, S., Jarnevich, J Stohlgren, Thomas, Waller, Donald M., Graham, Jim, 2010. Improving and integrating data on invasive species collected by citizen scientists. Biol. Invasions 12, 3419-3428. https://doi. org/10.1007/s10530-010-9740-9.

Dailianis, T., Akyol, O., Babali, N., Bariche, M., Crocetta, F., Gerovasileiou, V., Ghanem, R., et al., 2016. New mediterranean biodiversity records (july 2016). Mediterr. Mar. Sci. 17 (2), 608-626.

Darling, Emily S., Green, Stephanie J., O’Leary, Jennifer K., Isabelle, M., Côté, 2011. Indo-pacific lionfish are larger and more abundant on invaded reefs: a comparison of Kenyan and Bahamian lionfish populations. Biol. Invasions 13 (9), 2045-2051. https://doi.org/10.1007/s10530-011-0020-0.

de León, Ramón, Vane, Kim, Bertuol, Paulo, Chamberland, Valérie C, Simal, Fernando, Imms, Eseld, Vermeij, Mark J A, 2013. Effectiveness of lionfish removal efforts in the southern Caribbean. Endanger. Species Res. 22, 175-182. https://doi.org/10.3354/ esr00542.

Dimitriadis, Charalampos, Galanidi, Marika, Zenetos, Argyro, Corsini-Foka, Maria, Giovos, Ioannis, Karachle, Paraskevi, Fournari-Konstantinidoy, Ivoni, et al., 2020. Updating the occurrences of Pterois miles in the Mediterranean Sea, with considerations on the thermal boundaries and future range expansion. Mediterr. Mar. Sci. 62-69.

Esri, 2020. ArcGIS Pro. https://www.esri.com/en-us/arcgis/products/arcgis-pro/overvie W.

Galanidi, Marika, Zenetos, Argyro, Bacher, Sven, 2018. Assessing the socio-economic impacts of priority marine invasive fishes in the mediterranean with the newly proposed SEICAT methodology. Mediterr. Mar. Sci. 107-123.

Galil, B.S., Marchini, A., Occhipinti-Ambrogi, A., Minchin, D., Narščius, A., Ojaveer, H., Olenin, S., 2014. International arrivals: widespread bioinvasions in European Seas. Ethol. Ecol. Evol. 26 (2-3), 152-171. https://doi.org/10.1080/ 03949370.2014 .897651

Galil, Bella, Marchini, Agnese, Occhipinti-Ambrogi, Anna, Ojaveer, Henn, 2017. "The enlargement of the Suez canal - erythraean introductions and management challenges. Management of Biological Invasions 8 (2), 141-152. https://doi.org/ 10.3391/mbi.2017.8.2.02.

Galil, Bella S., Boero, Ferdinando, Campbell, Marnie L., James, T., Carlton, Cook, Elizabeth, Fraschetti, Simonetta, Gollasch, Stephan, et al., 2015. "'Double trouble': the expansion of the Suez canal and marine bioinvasions in the Mediterranean Sea. Biol. Invasions 17, 973-976. https://doi.org/10.1007/s10530014-0778-y.

Galloway, Katherine A., Porter, Marianne E., 2019. Mechanical properties of the venomous spines of Pterois volitans and morphology among lionfish species. J. Exp. Biol. 222 (6) https://doi.org/10.1242/jeb.197905.

Gattuso, J.P., Magnan, A., Billé, R., Cheung, W.W.L., Howes, E.L., Joos, F., Allemand, D., et al., 2015. Contrasting futures for Ocean and society from different anthropogenic CO2 emissions scenarios. Science 349 (6243). https://doi.org/10.1126/science. aac 4722 .

Gewing, Mey-Tal, Goldstein, Eyal, Buba, Yehezel, Shenkar, Noa, 2019. Temperature resilience facilitates invasion success of the solitary ascidian Herdmania momus. Biol. Invasions 21, 339-351. https://doi.org/10.1007/s10530-018-1827-8.

Golani, Daniel, Sonin, Oren, 1992. New records of the Red Sea fishes, Pterois miles (scorpaenidae) and pteragogus pelycus (labridae) from the eastern Mediterranean
Sea. Jpn. J. Ichthyol. 39 (2), 167-169. https://doi.org/10.1017/ CBO9781107415324.004.

Hackerott, Serena, Abel, Valdivia, Stephanie, J., Green, Isabelle M. Côté, Cox, Courtney E., Akins, Lad, Layman, Craig A., Precht, William F., Bruno, John F., 2013. Native predators do not influence invasion success of pacific lionfish on caribbean reefs. PloS One 8 (7). https://doi.org/10.1371/journal.pone.0068259.

Hamner, R.M., Freshwater, D.W., Whitfield, P.E., 2007. Mitochondrial cytochrome b analysis reveals two invasive lionfish species with strong founder effects in the western atlantic. J. Fish. Biol. 71 (Suppl. B), 214-222. https://doi.org/10.1111/ j.1095-8649.2007.01575.x.

Henderson, Evan Basil, 2012. Economic and ecological implications of interactions between lobsters and invasive lionfish in the Bahamas. Master's Thesis.

Hoegh-Guldberg, Ove, Bruno, John F., 2010. "The impact of climate change on the world's marine ecosystems. Science 328 (5985), 1523-1528. https://doi.org/ 10.1016/s0262-4079(10)61509-6.

Isabel, María, Martin, Victoria Y., Gelcich, Stefan, Stotz, Wolfgang, Thiel, Martin, 2021. Exploring diversity and engagement of divers in citizen science: insights for marine management and conservation. Mar. Pol. 124, 104316. https://doi.org/10.1016/j. marpol.2020.104316.

Jimenez, C., Petrou, A., Andreou, V., Hadjioannou, L., Wolf, W., Koutsoloukas, N., Abu Alhaija, R., 2016. Veni, vidi, vici: the successful establishment of the lionfish Pterois miles in Cyprus (levantine Sea). Rapid Communications Int. Mer Méditerranea 41, 417. http://ciesm.org/online/archives/abstracts/pdf/41/CIESM_Congress_2016_Kie 1_article_0417.pdf.

Johnston, Matthew W., Purkis, Sam J., 2014. Are lionfish set for a mediterranean invasion? Modelling explains why this is unlikely to occur. Mar. Pollut. Bull. 88 (1-2), 138-147. https://doi.org/10.1016/j.marpolbul.2014.09.013.

Katsanevakis, Stelios, Poursanidis, Dimitris, Hoffman, Razy, Rizgalla, Jamila, , Shevy Bat-sheva Rothman, Levitt-Barmats, Ya'arit, Hadjioannou, Louis, et al., 2020. Unpublished mediterranean records of marine alien and cryptogenic species. BioInvasions Records 9 (2), 165-182.

Kimball, Matthew E., Miller, John M., Whitfield, Paula E., Hare, Jonathan A., 2004. Thermal tolerance and potential distribution of invasive lionfish ( Pterois volitans) miles complex ). on the East Coast of the United States" 283, 269-278.

Kleitou, Periklis, Jason, M., Hall, Spencer, Savva, Ioannis, Kletou, Demetris, Hadjistylli, Margarita, Azzurro, Ernesto, Katsanevakis, Stelios, et al., 2021. The case of lionfish (Pterois miles) in the Mediterranean Sea demonstrates limitations in EU legislation to address marine biological invasions. J. Mar. Sci. Eng. 9 (3) https://doi. org/10.3390/jmse9030325.

Kleitou, Periklis, Savva, Ioannis, Kletou, Demetris, Jason, M., Hall-Spencer, Antoniou, Charalampos, Christodoulides, Yiannis, Chartosia, Niki, et al., 2019. Invasive lionfish in the mediterranean: low public awareness yet high stakeholder concerns. Mar. Pol. 104 (March), 66-74. https://doi.org/10.1016/j. marpol.2019.02.052.

Kletou, Demetris, Jason, M., Hall, Spencer, Kleitou, Periklis, 2016. A lionfish (Pterois miles) invasion has begun in the Mediterranean Sea. Marine Biodiversity Records 9 (1), 1-7. https://doi.org/10.1186/s41200-016-0065-y.

Larson, Eric R., Graham, Brittney, Achury, Rafael, Coon, Jaime J., Daniels, Melissa K., Gambrell, Daniel K., Kacie, L., Jonasen, et al., 2020. "From EDNA to Citizen Science : Emerging Tools for the Early Detection of Invasive Species, vols. 194-202. https:// doi.org/10.1002/fee.2162.

Lesser, Michael P., Slattery, Marc, 2011. Phase shift to algal dominated communities at mesophotic depths associated with lionfish (Pterois volitans) invasion on a Bahamian coral reef. Biol. Invasions 13 (8), 1855-1868. https://doi.org/10.1007/ s10530-011-0005-z.

Mack, Richard N., Simberloff, Daniel, Lonsdale, W Mark, Evans, Harry, Clout, Michael, Bazzaz, Fakhri A., 2000. Biotic invasions: causes, epidemiology, global consequences, and control. Ecol. Appl. 10 (3), 689-710. https://doi.org/10.1890/ 0012-9623, 2008)89[341:iie]2.0.co;2.

Magory, Tali, Suresh Kumar, R., Nair, Manoj, Hauber, Mark E., Dor, Roi, 2020. Innovation and decreased neophobia drive invasion success in a widespread avian invader. Anim. Behav. 163, 61-72. https://doi.org/10.1016/j. anbehav.2020.02.012.

Maljković, A., Van Leeuwen, T.E., Cove, S.N., 2008. Predation on the invasive red lionfish, Pterois volitans (pisces: scorpaenidae), by native groupers in the Bahamas. Coral Reefs 27 (3), 501. https://doi.org/10.1007/s00338-008-0372-9.

Mavruk, Sinan, Avsar, Dursun, 2008. Non-native fishes in the mediterranean from the Red Sea, by way of the Suez canal. Rev. Fish Biol. Fish. 18 (3), 251-262. https://doi. org/10.1007/s11160-007-9073-7.

Mumby, Peter J., Harborne, Alastair R., Brumbaugh, Daniel R., 2011. Grouper as a natural biocontrol of invasive lionfish. PloS One 6 (6), 2-5. https://doi.org/ 10.1371/journal.pone.0021510.

Myles-Gonzalez, Emelia, Gary, Burness, Yavno, Stan, Anna, Rooke, Michael, G., Fox, 2015. To boldly go where No goby has gone before: boldness, dispersal tendency, and metabolism at the invasion front. Behav. Ecol. 26 (4), 1083-1090. https://doi. org/10.1093/beheco/arv050.

Özbek, Özgür, Elif, Mavruk, Sinan, Saygu, İsmet, Öztürk, Bayram, 2017. Lionfish distribution in the eastern mediterranean coast of Turkey. Journa of Black Sea/ Mediterranean Environment 23 (1), 1-16.

Peake, Jonathan, Bogdanoff, Alex K., Layman, Craig A., Bernard Castillo, , Kynoch Realemunroe Jennifer, Chapman, Kristen, Dahl, William, et al., 2018. Feeding ecology of invasive lionfish ( Pterois volitans and Pterois miles ) in the temperate and tropical western atlantic. https://doi.org/10.1007/s10530-018-1720-5.

Poursanidis, D., 2015. Ecological niche modeling of the invasive lionfish Pterois miles (bennett, 1828) in the Mediterranean Sea. In 11th Panhellenic Symposium on Oceanography and Fisheries, Mytilene. Levos Island, Greece, pp. 621-624. 
Poursanidis, Dimitris, Kalogirou, Stefanos, Azzurro, Ernesto, Parravicini, Valeriano, Bariche, Michel, 2020. Habitat suitability , niche unfilling and the potential spread of Pterois miles in the Mediterranean Sea. Mar. Pollut. Bull. 154 https://doi.org/ 10.1016/j.marpolbul.2020.111054.

Ramos-Ascherls, Zullaylee, Williams, Ernest H., Bunkley-Williams, Lucy, Tuttle, Lillian J., Sikkel, Paul C., Hixon, Mark A., 2015. Parasitism in Pterois volitans (scorpaenidae) from coastal waters of Puerto Rico, the Cayman Islands, and the Bahamas. J. Parasitol. 101 (1), 50-56. https://doi.org/10.1645/13-422.1.

Riisgård, Hans Ulrik, Larsen, Poul S., 2010. Particle capture mechanisms in suspensionfeeding invertebrates. https://doi.org/10.3354/meps08755, 418, 255-293.

Rius, Marc, Shenkar, Noa, 2012. "Ascidian introductions through the Suez Canal : the case study of an indo-pacific species. Mar. Pollut. Bull. 64 (10), 2060-2068. https:// doi.org/10.1016/j.marpolbul.2012.06.029.

Rojas-Vélez, Stephanía, Tavera, Jose, Acero, Arturo, 2019. Unraveling lionfish invasion: is Pterois volitans truly a morphologically novel predator in the caribbean? Biol. Invasions 21 (6), 1921-1931. https://doi.org/10.1007/s10530-019-01946-6.

Sandahl, Andrew, Tøttrup, Anders P., 2020. Marine citizen science: recent developments and future recommendations. Citiz. Sci. Theory Pract. 5 (1), 1-11.

Savva, Ioannis, Chartosia, Niki, Antoniou, Charalampos, et al., 2020. They are here to stay: the biology and ecology of lionfish (Pterois miles) in the Mediterranean Sea. J. Fish Biol. 1-15. https://doi.org/10.1111/jfb.14340. April.

Sellers, Andrew J., Ruiz, Gregory M., Leung, Brian, Torchin, Mark E., 2015. Regional variation in parasite species richness and abundance in the introduced range of the invasive lionfish, Pterois volitans. PloS One 10 (6), 1-15. https://doi.org/10.1371/ journal.pone.0131075.

Simberloff, Daniel, Martin, Jean Louis, Genovesi, Piero, Maris, Virginie, Wardle, David A., Aronson, James, Courchamp, Franck, et al., 2013. "Impacts of biological invasions: what's what and the way forward. Trends Ecol. Evol. 28 (1), 58-66. https://doi.org/10.1016/j.tree.2012.07.013.
Smith, Nicola S., Isabelle, M., Côté, 2021. Biotic resistance on coral reefs? Direct and indirect effects of native predators and competitors on invasive lionfish. Coral Reefs. https://doi.org/10.1007/s00338-021-02117-7.

Stern, Nir, Jimenez, Carlos, , Mehmet Fatih Huseyinoglu, Andreou, Vasilis, Hadjioannou, Louis, Petrou, Antonis, Öztürk, Bayram, Golani, Daniel, Shevy, B., Rothman, S., 2019. "Constructing the genetic population demography of the invasive lionfish Pterois miles in the levant basin, eastern mediterranean." mitochondrial DNA Part A: DNA mapping. Sequencing, and Analysis 30 (2), 249-255. https://doi. org/10.1080/24701394.2018.1482284.

Torchin, Mark E., Mitchell, Charles E., 2004. Parasites, pathogens, and invasions by plants and animals. Front. Ecol. Environ. 2 (4), 183-190. https://doi.org/10.1890/ 1540-9295(2004)002 [0183:PPAIBP]2.0. CO;2.

Turan, C., 2020. Species distribution modelling of invasive alien species; Pterois miles for current distribution and future suitable habitats. Global Journal of Environmental Science and Management 6 (4), 429-440. https://doi.org/10.22034/ gjesm.2020.04.01.

Ulman, Aylin, Tunçer, Sezginer, , Inci Tuney Kizilkaya, Zilifli, Aytŭ̆, Alford, Polly, Giovos, Ioannis, 2020. The lionfish expansion in the Aegean Sea in Turkey: a looming potential ecological disaster. Regional Studies in Marine Science 36. https://doi.org/10.1016/j.rsma.2020.101271.

Weis, Judith S., Sol, Daniel (Eds.), 2016. Biological Invasions and Animal Behaviour. Cambridge University Press, Cambridge, United Kingdom.

Whitfield, Paula E., Muñoz, Roldan C., Buckel, Christine A., Degan, Brian P., Freshwater, D Wilson, Hare, Jonathan A., 2014. Native fish community structure and indo-pacific lionfish Pterois volitans densities along a depth-temperature gradient in onslow Bay, North Carolina, USA. Marine Ecology Pr 509, 241-254. https://doi.org/ 10.3354/meps10882. 